\title{
REVIEW ARTICLE \\ SOME OBSERVATIONS ON SPECIES COMPOSITION AND DETERIORATION OF CROP PLANTATIONS AND FOREST FLORA BY PORCUPINES IN CONSORT WITH CONTROL TECHNIQUES
}

\author{
MUHAMMAD SARWAR* \\ Agricultural Biotechnology Division, National Institute for Biotechnology and Genetic Engineering (NIBGE), \\ Faisalabad 440 oo, Punjab, Pakistan
}

\begin{abstract}
The goal of this article is to inform community regarding porcupines damage, and deliver guidelines for their harmless, real and liable elimination. The utmost apparent attribute of porcupines is their extensive, piercing and shakable quills, which shelter backs of the physiques that make them hit, as a threatening to probable raiders. In general, porcupines occur the maximum in mountainous and gravelly states, however these may adjust in many territories like extremely wet plantations and somewhat territory comprising of prairies, foothills, deserts and tropical forests. Porcupines can become a pest by eating of carrots and other root vegetables, clovers, roots, fruits as well as foraging on the farm crops. A definite indication of porcupine burrow is a mound of feces at entering site of cave or hollow tree. In this global region, Hystrix indica Kerr is most plentiful and scattered species, and has been familiarized as a severe pest of fruit orchards, vegetables, flowering plants, forage grasses in pastures or rangelands and traditional as well as non-traditional crops. When porcupines inflict optimum damage, then their control actions must be adopted. A pest controlling expert can provide skill to recognize the porcupines problematic and decide the superlative promising way out to decide the pest annoyance. Prior to executing a loss managing method, evaluate the porcupines incidence by means of watching for shattered quills, fecal masses beneath nourishing and sleeping plants, or distinctive injury marks to trees in a region. Manipulate habitat to attract more natural predators to control porcupine populations, place aluminum flashing around mature tree trunks and enclose small trees with wire baskets, and enclosure areas with electric or nonelectric fencing, to stop porcupines from gnawing at their bark. Implement forest management practices to reduce food supply and some wood preservatives applied to trees, and use of poison baits may provide partial damage relief. During late spring and summer activity periods, shooting of pest is most effective option, and use steel leg-hold traps lured by salt-soaked ingredients and placing proximate to alive burrows or else frequently used tracks.
\end{abstract}

Keywords: Vertebrate pest, Wildlife damage management, Plant deterioration, forest plantation, Hystrix indica

\section{INTRODUCTION}

Rodents (order Rodentia) are any living species of mammals (wherein new born is suckled by the mother on milk from distinct mammary glands) categorized by lower and upper sets of ever-growing rootless incisor teeth [1-6]. Porcupines are a rodent occurring in two leading constituencies of the biosphere, therefore experts have grouped these either into Old World porcupines within family Hystricidae or else New World porcupines of Erethizontidae family [7].

\section{Old World Porcupines (family Hystricidae)}

Within the Hystricidae family of Old World porcupines, there are 11 species in three genera. Species of Old World porcupines are found in Asia, Europe and Africa, and round about cases are African brush-tailed porcupine,
North African crested porcupine and Indian crested porcupine [8]. Old World crested porcupines bear quills on back which are able to arise as a crest that commences from the upper of head and reaches below to shoulders. Every quill is manifested by white and black marks and many of these are nearly equal to $51 \mathrm{~cm}$ in length, while smaller rigid quills are nearly $20 \mathrm{~cm}$ lengthy. The lengthy, workable quills perform like safeguard furs and appear as skirt at what time animal is endangered, and the skirt is able to be raised through creating the porcupine to look like double to thrice times greater. Old World porcupines pass most of their natural life on the surface of ground and these are to a certain degree communal and on occasion wandering in couples. These like to live somewhere within rock crevices, caves, hovels or dens which these may well have excavated. These occasionally relax in unrestricted aardvark hovels that these can amend to outfit their

\section{Received 29 March 2018; Accepted 20 May 2018 \\ *Corresponding Author \\ Muhammad Sarwar \\ Agricultural Biotechnology Division, National Institute for Biotechnology and Genetic Engineering (NIBGE), Faisalabad 440 oo, Punjab, Pakistan \\ Email: drmsarwar64@gmail.com}

(This article is open access and licensed under the terms of the Creative Commons Attribution License (http://creativecommons.org/licenses/by/4.o/) which permits unrestricted, use, distribution and reproduction in any medium, or format for any purpose, even commercially provided the work is properly cited. Attribution - You must give appropriate credit, provide a link to the license, and indicate if changes were made. 
personal requirements. Old World porcupines are tremendous swimmers but these do not hike or jerk properly. Old World porcupines eat berries, roots, fruits and plant bark, however in rural parts, these can forage on cultivated crops, for instance, potatoes, melons groundnuts and pumpkins [9, 10].

Old World porcupine species are principally land-dwelling, even though Southeast Asian long-tailed porcupine (Trichys fasciculata) as well can rise to shrubs and trees for foodstuff. This species is the tiniest fellow of the family, weigh up a lesser than $4 \mathrm{~kg}$, has to some extent rat-like look and nearly a half meter in length, without the tail that is almost half of the body length. Brush-tailed porcupines of genus Atherurus, travel quickly above the ground and are able to hike, swim and jump. These from time to time assemble together for feeding and resting. Species of longtailed and Brush-tailed porcupines lodge in caves, rocky crevices, hollow trunks, tree roots, uninhibited dens otherwise wind-swept cracks alongside of stream banks and termite mounds.

Short-tailed porcupines of genus Hystrix, are the biggest species, have weigh equal to $30 \mathrm{~kg}$, by bodies nearly one meter lengthy and tail 8-17 $\mathrm{cm}$ in length. These travel sluggishly in a heavy gait, however will break into a hurry or race as soon as are upset. Similar to the North American porcupine, these gnaw bones and antlers to complement their herbivorous food that comprises the below ground pars of shrubberies, cultivated crops and dropped fruits as well plant bark [11; 12]. Frequently take shelter in hovels, rock cracks, Hystrix species too dig dens of their own which may turn into widespread after many years of living. European inhabitants of Hystrix cristata hide-out into their burrows in the course of rainstorms and unpleasant influences, however these do not lie dormant. This species lives in Sicily and Italy, wherever it may perhaps have been brought together by way of human, and in Britain somewhere it is surely make known [13; 14]. The Atherurus species likewise have specified heavy quills that are used as clatters [15].

\section{New world porcupines (family Erethizontidae)}

The New World porcupines live in South, North and Central America, and few specimens are the Brazilian porcupine, Mexican hairy dwarf porcupine and Canadian porcupine [16]. Spines of New World porcupines are greatly reduced measuring around $10 \mathrm{~cm}$ in length, however these perform fair function also. As soon as endangered, New World porcupine upright quills which protrude in several ways, similar to a pincushion. Also, New World porcupines are recognized to hit out at raiders through hitting on these by their quill-laden tails and in the course of combats, as well prattle their teeth to produce aggressive sound [17). New World porcupines pass much of their time singly otherwise live in couples and make passages within the shrubs. These can burrow in trees logs or in tangled tree roots and also make nests in rock crevices or bushes. Altogether, New World porcupines bear stretched and hooked claws which are tremendously designed for hiking. Prehensile-tailed porcupines bear tails which can be curled round twigs and affix to a tree. New World porcupines mainly eat stems, leaves, roots, flowers, seeds, nuts, fruits, tubers, berries, corn, pine needles and bark, aquatic vegetation, and meadow grass, whereas more or less takings fruits from various plantations. The North American porcupine has received a wicked repute intended for destroying of ornamental trees and timber through peeling off bark from the trunks $[18 ; 19]$.
The North American porcupine (Erethizon dorsatum), typically weighs less than $7 \mathrm{~kg}$ and is the biggest species in the family although males sometimes develop considerably longer. This one has body equal to $80 \mathrm{~cm}$ in length by having tail up to $30 \mathrm{~cm}$ long. Both body and tail are protected by a total of 30,000 or else further hollow quills. On ground surface, the porcupine walks alongside but unable to jump, on the trees it hikes sluggishly, on the other hand has an excellent balance, and in the water can swim fine. As soon as comes near, the individual offers its tail and when attacked, it will react with its powerful and muscular tail in contradiction of the assaulter. The North American porcupine dwells in plantations, together with timbered ranges alongside watercourses in tundra, desert and prairie expanses. This one is occasionally visible for the period of the day and the merely New World porcupine which is land-dwelling along with arboreal. This one may stay in trees, however likewise burrows in hollow plants, stumps or logs, besides rock crevices, caves, tunnels, or snowbanks. Individuals occupying in coniferous timberlands pass considerably greater period above the ground. Whereas, individuals existing in deciduous and miscellaneous timberlands, on the other hand, are further frequently observed in the bushes that are their basis of diet. For the period of summer and spring, their food comprises leaves, buds, stems, twigs, flowers, roots, nuts, seeds and berries. During winter, bark of trees, the inner cambium layer and evergreen needles come to be the main bases of their diet. Bones and antlers are also chewed upon to obtain calcium and further minerals which support in quills development. Even though porcupines do not overwinter through the wintertime, these keep on in their burrows for the period of mainly cold or severe meteorological conditions. These are normally lonely, however from time to time burrow in crowds [20; 21].

Predators of New World porcupines comprise eagles, martens, wolverines, great-horned owls and pythons. One predator of porcupine, the fisher, is capable to flip the North American porcupine onto its back, thus exposing its exposed abdomen [22].

Entirely, porcupines are nightly pests and fairly adjustable, and can found in a diversity of territories on condition that there is shrubbery. Totally, porcupines have an excessive common sense of odor and create a rapid effort on existing diet, these herbivores bear piercing, chisel-like anterior teeth. These mainly have a habit of to feed single-handedly reasonably than in crowd, with the exception of a mammy by way of its young known as porcupettes, which are not born by harsh or else pointed quills. Base coloring ranging from grayish brown from side to side dark brown to blackish, however this dyeing is covered by multicolored arrangements of white, yellow and orange or black owing to bands on the spines [23]. Porcupines is the prickliest of rodents and all bear soft fur, however on their back, sides and tail these are generally diverse by sharp needle-like quills, which is most recognizable feature. Quills are fairly amended hairs made up of keratin, which do not shield to underneath of porcupine and bear muscles at the base of every quill that permit them to arise as soon as the pest is agitated or terrified. These quills normally stay horizontal till a porcupine is endangered and then jump to care as a convincing warning. Certainly, when porcupine knockouts an animal by its quills, the quills develop inserted in the body of animal. Old World porcupines have quills implanted in groups, while in New World porcupines single quills are spread with spines, underfur and hair. Entirely bear small, stout legs, however their tails range 
from little to lengthy, having some being prehensile. Porcupines are amongst the third-largest of the rodents, after the capybara and the beaver. Maximum porcupines are around 60-90 cm in length, having a $20-25 \mathrm{~cm}$ long tail and weigh up 5-16 $\mathrm{kg}$ [24; 25].

Porcupines practice to usage of odor is while their eyesight and sound have been unsuccessful. An offensive odor is created from the skin beyond the tail in whiles of tension, which is habitually perceived by erection of quill. When the above practices miscarry, the porcupine will attack to predators by running to sideward or rearward. Furthermore, porcupine's tail is capable of strike in the track of target and when connection is done, the quills might be pierced into the predator initiating wound or passing away [26].

The biggest porcupine is the North African crested porcupine and this one develops up to $90 \mathrm{~cm}$ in length. The tiniest is the Bahia hairy dwarf porcupine that develops up to $38 \mathrm{~cm}$ in length. Porcupines usually weigh up 1.2 to $35 \mathrm{~kg}$ depending upon species and their tails is able to develop up to 20 to $30 \mathrm{~cm}$ long. Porcupines come to be mature sexually at an age of two years and contrasting to most of other rodents, these produce simply a single progeny in each year, needing a pregnancy time of equal to seven months. Adults porcupine mate in late summer and early fall (September to November), and are very voiced for the duration of mating period. Males habitually battle over females, and make a decorative dance and sprays urine on the skull of the female that signs her to lower its quills and move spiny tail to the sideway for copulating. The quills raid each other while the tail is shaken to create lurid sounds used to transfer with other individuals (particularly for the duration of mating) and to inform predators. The female porcupine will offer delivery to the baby seven months afterward the copulating procedural [27].

Female porcupines transport their newborn for a maturation age of 16 to $31 \mathrm{w}$ and subjected to species offer delivery to one to three litters at a phase. At birth, porcupettes are nearly 3 percent of mother's weight and these have soft quills, which are not harmful to the mother for the reason that of safety from the placental sac and predominating moisture content, but these toughen in a few days. As soon as the baby is born, its quills are soft and these normally solidify nearly an hour afterward delivery. The baby starts to feed on diet afterward simply a pair of days. The female nurses to young baby by a pair of nipples situated below the armpits while one more pair on the belly. For about a period of six months the baby will stay with its mother. Following the $210 \mathrm{~d}$ of development time, nursing by mother lasts for just about $127 \mathrm{~d}$. As a result, females pass $337 \mathrm{~d}$ of the year either being pregnant or lactating. Porcupettes mature in 9 mo to 2.5 y subjected to species and can live up to $15 \mathrm{y}$ in the wild [28].

\section{Human and porcupines conflict}

By the way, as human populations multiply, humans and porcupines consider themselves in progressively very neighboring lodgings. Porcupines are generally recorded as slightest fear or as weak, anyhow the species recorded as at risk include the bristle-spined porcupine and the Phillipine porcupine. There are presently no species recorded as threatened, however, more or less species do not have an adequate information to reach a definite conclusion regarding their position. Porcupines are nightly that means these sleep for the duration of the day and are dynamic for the period of the night, and these feed for diet in the course of the night. Porcupines are herbivores, this means these consume generally plants, however many porcupines like to feed on wood and consume greatly stems and barks. These too feed upon fruits, seeds, tubers, nuts, buds, leaves and grasses. Yet, these do not forage upon eat meat, but porcupines to sharpen their teeth gnaw on bones. Likewise, bones provide them essential minerals, such as salt and calcium, to retain these in good physically. Porcupines are furthermore recognized to feed upon bugs and small lizards from time to time. As soon as porcupine population is adjacent to crop growing areas these surge well and may turn out to be severe agricultural pests. These are smoked to come out of their dens and hunted with nets, dogs and spears. These rehearses if adopted can eradicated them from heavily established regions [29; 30].

\section{The Indian crested porcupine Hystrix indica Kerr}

The Indian crested porcupine (Hystrix indica Kerr), or Indian porcupine, is one of the world's largest rodents belonging to the Old World porcupine group, and native to the Middle East and southwest and central Asia. Body of crested porcupine measures between $70-90 \mathrm{~cm}$ (from the nose to the base of the tail), by the tail adding a further 8$10 \mathrm{~cm}$ and weighing $11-18 \mathrm{~kg}$. It bears wide feet having stretched claws employed for digging. In February and March, Indian crested porcupines mate and incubation takes on an average of $240 \mathrm{~d}$. Single female offers delivery to one clutch of two to four progeny each year and newborn are abundantly weaned up to $13-19$ w next to birth, however offspring continue to live with parents in the burrow and siblings until erotic adulthood is achieved nearby $2 \mathrm{y}$ of oldness. The crested porcupine is generally monogamous and adult parentages inhabit in the burrow by their progeny all over the year. The lifetime of wild crested porcupines is unfamiliar, however the ancient identified caged individual has a female that survived to be 27.1 y old [31, 32].

Results of a study revealed that the porcupine depends on plant material from both cultivated and non-cultivated lands, damages the field crops as well as agroforestry trees [33]. Because of their elastic ecological easiness, crested porcupines inhabit an extensive variety of territories. These have a preference for stony hillsides, however are similarly share in hot and moderate forests, shrub lands, plantations, grasslands and orchards. These eat a diversity of agricultural and natural plant materials, together with fruits, grains, roots, bulbs, tubers and drupe, accompanied by small vertebrates and insects. These porcupines are able to perform as considerable surroundings convertors as soon as digging soil for tubers. These are moreover wellthought-out severe pests of agriculture in several fragments of their range because of their sense of taste for cultivated crops. For these reasons, these are often regarded as a nuisance [34].

The Indian crested porcupine, $H$. indica, is an over-all hunter that feats an extensive diversity of wild and cultivated plants, and devour above ground along with subsurface plant material. Crops of commercial significance, for instance, sugar cane, wheat, maize, groundnut and melon are rigorously impaired in the watered grasslands and rainfed belt. Amongst the vegetables, bitter gourd, pumpkin, okra and onions are severely injured. On the other hand, for the reason that these are damaging to agricultural crops and gardens, and regardless of being well-thought-out a pest, crested porcupines perform a key part in dispersal of pollens and seeds [35]. 


\section{Damage and damage identification due to porcupines}

Financial sufferers may be significant due to porcupines nourishing on ornamentals, orchards and forest plantings along with on rawhide and further humanoid equipment. Generally, porcupines are accepted with the exception of as soon as orchards, high-value ornamental plantings, commercial timber or nursery floras are spoiled by branch clipping, basal gnawing or girdling. Occasionally, porcupines can make thin to compact and congested forestry stands. Frequently, owing to pest's damage tree breadth development is abridged. Their liking for mistletoe by way of a nutrition is an advantage. Most of porcupine's loss happens for the duration of the winter as soon as forested foliage come to be an essential food. A widespread aggravating of twigs, shoots and bark is a sign of porcupine's invasion. Vulnerable plants comprise poplar, elm, pine, spruce, abundant shrubs and fruit-bearing trees. If girdling of the tree bark is intense, it will destroy to the plant. Porcupines are able to harm succulent plants, fruits and vegetables in summer [36].

Cut shoots on new snow, pathways and aggravating on trees are valuable ways of injury identification. Due to partial girdling, trees are frequently distorted. Porcupines trimmed branches and twigs that drop to the ground or on snow, frequently offer diet to deer and other mammals. An extensive secondary special effect of their nourishing originates from exposing of the tree sapwood to attack by insects, diseases and birds. This disclosure is vital to several species of wildlife for the reason that hollow or diseased trees offer accommodation and nest locations. Porcupines sometimes cause significant damages by injuring to sweet corn, alfalfa and small grains. These gnaw on wood objects, decks and other hand tools while looking for salt. These damage siding on cottages at what time in search of plywood resins. Since these are generally nocturnal, they are capable to go about their business unnoticed, but if landlords notice a lot of shavings or frass under a newly damaged tree, it could be from a porcupine. Even though porcupines are pronounced tree hikers and may reside on quite a lot of species of trees, these appear to have a preference for hemlock, ponderosa, white birch, elm, spruce, poplar and pinion [37].

Porcupines compromise a significant hazard to dogs, which by no means seem to learn to avoid them. Domestic stock seldom will nuzzle to a porcupine and might be seriously damaged if quills are not detached quickly. Similar to wholly rodents, teeth of porcupines develop persistently, therefore, these have an excessive prerequisite to aggravate in order to retain their teeth crushed to a short enough length. Sometimes, porcupines discover buildings, open air sheds and other wooden arrangements together with piers and boat houses where these may extremely harm to beams and other maintenance arrangements by their aggravating. Porcupine damage to homes, building structures and garden regions is on the enlargement. Porcupines have a taste for salt, juicy foliage, fruitlets, vegetables, wooden wheel barrow handles, wooden tool handles, porch furniture, boat oars, saddles, toilet seats, tires or whatsoever else that can have salt on them or some other minerals. Wooden tool handles engross salt from sweat that certainly appeal to feeding porcupines. Vehicle tires that move on salted roads in the winter absorb several minerals which can attract porcupines to forage on the delicious stamp [38].

\section{Prevention and control of porcupines}

Usually, porcupines are accepted apart from where highvalue nursery stock, trees, ornamental plants and commercial timber are injured by gnawing, girdling or clipping. Every so often, tree diameter growth is constrained or fresh seedlings are destroyed owing due porcupine's nourishing. Porcupine's injury can be condensed or stopped by a number of methods such as exclusion, removal or repellents. Porcupine's control is accomplished in one or other ways. Just the once, landlords notice its action, it is vital to stopover this one timely. Porcupines will move a number of kilometers intended for a food, however, as soon as these locate an upright habitation to forage, they will consume the whole things accessible prior to depart. For the reason that of this pattern, landlords should grasp a fresh injury and force those to move or else it will just continue. This may be completed through either by eliminating the diet source they need to forage on or by creating it flavor dreadful thus they solely permit it alone. Tools, small wooden objects and yard furniture should generally be detached and consequently porcupines will not have contact to them. But, structures and trees are permanently present a challenge when repelling porcupines. The sides of buildings, large wooden furniture, sheds and further large items not easy to transfer can be treated with liquid repellent that has very little odor to people, but lethal to animals for its repulsive. Just spray the external portion of whatever thing the porcupines need to consume and the pest will discontinue [39].

\section{Exclusion}

One and only of the utmost operational methods to keep porcupines out of backyard, is to form a fence to retain them out. However, this is not the low-cost method to adopt because fencing is certainly pricey and it needs a lot of conservation, but if landlords have several difficulties with animals ingestion their flowers, vegetation and orchard, it may be assets for expenses of the cash. Landlords may go with a wire mesh fence or even a white picket fence, however, either one goes with, create assure that it goes as a minimum of one-foot overhead and underneath ground. It saves animals from digging below or hopping above the fence. Fencing of small gardens, tree plantings and orchards is real in decreasing of porcupine's harm. Electric fences are operational while the plane electric wire is positioned $3.8 \mathrm{~cm}$ above a $46-\mathrm{cm}$ poultry wire. A 10-to 15 -cm electric fence can be improved by painting molasses on the wire. Porcupines will hike fences, however a hanging wire striped round the top of the fence at a $65^{\circ}$ angle to the upright wire will disappoint them. Entirely encircle small trees with wire baskets, or enclose the trunks of fruit and ornamental trees with $70-\mathrm{cm}$ bands of aluminum flashing to decrease loss [40].

\section{Animal removal}

Maximum of plant injury can be decreased by eliminating of the porcupine. Porcupines from neighboring regions will typically not reinvade the region for some time, every so often for quite a few months. Accordingly, animal elimination is an operational stoppage and controller practice for this pest [41].

\section{Cultural methods}

Dispersed forest outlooks are susceptible to porcupine's injury for the reason that forest floor vegetation can flourish more. Porcupine densities are typically condensed 
in closed-canopy stands anywhere underwood foliage is negligible.

\section{Repellents}

Escape the usage of wood preservatives which are metalsalt solutions, because these will attract to porcupines. Repellents like skoot or thiram-based combinations are the produces which can be used for porcupine. Such foodstuffs are able to be sprayed or brushed on maximum plants and these provide a bitter and unpleasant flavor to the pest. Make sure of not applying repellents to vegetation generally raised for animal or human ingestion because the repellents will form to plants unpalatable. Landlords may as well make usage of an ultrasonic emitter to retain the pest gone, however this once more is not $100 \%$ sure to give success. Likewise, there also exist water repellent systems such as motion activated sprinkler systems which will spray to porcupine when this moves toward nearby place wherever it is set up [42].

Field trials have been piloted to conclude the effectiveness of aluminium phosphide (3 gm tablets) in randomly selected burrows against Indian crested porcupine. Resultantly, 100\% decrease in den action has been noted, through applying of 8 tablets/burrow, $85 \%$ by 6 tablets/burrow and $75 \%$ by using of 4 tablets/burrow. In characterized burrows, $100 \%$ decrease in den action has been noted while 4 tablets of aluminium phosphide for each burrow applied in minor (circumference 100.2 \pm 2.93 $\mathrm{cm}), 6$ tablets in average $(127.7 \pm 0.93)$ and 8 tablets in big (157.4 \pm 2.44$)$ dimension burrows. So, aluminium phosphide fumigation is recommended by way of inexpensive and practicable tactic in man-made forest plantations for the control of porcupines [43].

The field efficacy of coumatetralyl bait (0.0375\%) studied against $H$. indica revealed that as a result of baiting, dead porcupine showed symptoms of anticoagulant poisoning. Analysis of post-treatment porcupine activity showed no signs of activity, indicating $100 \%$ reduction of porcupine population on floriculture farm [44].

\section{Trapping}

Another option that landlords can adopt to get rid of porcupine is trapping to these, however, this needs patience and is time consuming. Landlords may purchase Steel leg-hold traps from nearby garden or else hardware supplies and an animal control officer can set the traps. Lure the trap by a yummy snack such as sunflower seeds and peanut butter, and wait for pest trapping. Check the trap every day and once it is trapped, put it somewhere else to a wooded area or fine park which is as a minimum of $15 \mathrm{~km}$ away from farm house. Cubby sets with salt baits, coyote urine scent-post sets near burrows and spoiled parts, and trail sets in front of dens, are effective. Trail sets and scent-post might be observed every day to relieve nontarget animals which are trapped. Leg-hold traps ought to be bedded, leveled and firmly placed, and offset to some extent to the side of the trail [45].

The Conibear body-gripping trap may be lured by a saltsoaked material and sited in burrow entries to trap and destroy porcupines. Precaution needs to be taken to escape attract of non-target animals, as salt invites to several other animals. Porcupines are somewhat easy to live trap by homemade box traps or large commercial cage traps. Install the live trap at burrow entrances or else in the surrounding area of damage and lure with a salt-soaked piece of wood, sponge or cloth. Wherever permissible, transfer to the porcupine $40 \mathrm{~km}$ otherwise further to make certain that it does not arrive back. As maximum regions of an appropriate territory hold great porcupine populations, the porcupine repositioning usually is neither useful nor caring, for the reason that the hosted animal can have a reduced opportunity of existence. Install the trap at the base of a large tree or else a sloping one close the impairment spot. Lure a small cubby (enclosed space) with a salt-soaked slice of wood or leather, otherwise salt mixed with cooking oil or vegetable bits such as turnip or carrot, etc. $[46 ; 47]$.

\section{Snaring}

Once porcupines raid an urban public, snaring might be an easiest way of pest elimination. During various occasions, a pole snare may be maneuvered over the porcupine's head and the animal then can be picked up into a carrying box. Take into account that the pole must be sufficient stout to lift up more than $15 \mathrm{~kg}$ weight and adequate lengthy to securely herd the porcupine or to defend against somewhat quick physical attack from the animal [48].

\section{Shooting}

A determined shooting and killing of porcupines may be real in decreasing their density in areas which need safeguard. To some extent, dwellers can chase porcupine all over the year on lands where night hunting is legal and with right of access. Throughout wintertime, porcupines are vigorous and may be traced in the snow and gunshot by a.22-caliber rifle otherwise a revolver. Frequently, porcupines gather nearby good burrowing spots and widely girdle plants in the region. In such dwellings, the great numbers of porcupines can be killed by gunfire. By way of the porcupine moves through the snow, it creates after a constant track or groove approximately $30 \mathrm{~cm}$ extensive, accordingly, trail and trace the pest and fire it by a small caliber gun [49].

\section{Other control considerations}

Porcupines are highly moveable and repetitively re-occupy in controlled regions. Their widespread control is not appropriate as it would involve a broad elimination of porcupines. Always attempt to bound fatal porcupine control to single animal producing injury. Practice a fencing to defend crop species of high-value. Within regions of great porcupine inhabitants, attempt to plant ornamentals which are not their favored diets. Primarily, fishers are a predator of porcupines, however quills have been observed inserted in bears, bobcats, coyotes, foxes, wolves, lynxes, cougars and even great horned owls. These predators exterminate to a porcupine through piercing of its vulnerable surface or else by way of reversing it over to uncover the susceptible underneath. Rigorous control of such predators can impact in increases of porcupine's population [50].

\section{CONCLUSION}

This article is envisioned to deliver learning and facts regarding porcupines, so that accordingly public may create a knowledgeable choice if they want to cope with a problem of porcupine. Porcupines are among remarkable creatures and perform a significant part in bionetwork functioning. These are amongst a small number of animals that can be simply trapped by weaponless persons and their quills have been used in different beautifications for centuries, whereas their fur is actually common among fly fishermen by using for fly fishing lures. When its inhabiting concentration on that action of control must be 
started to check a growing damage from touching of the financial harm level, then damage control actions must be adopted. Over-all a complete suppression of porcupines in an ecological unit is neither a useful decision nor biologically judicious. Prior to applying an injury control practice, judge the occurrence of porcupines through observing of cracked or shattered quills, typical injury symbols to trees, and fecal masses beneath resting and nourishing plants within an area. Select the best competent and cost nominal injury managing methods which are well-matched by the way of porcupine's periodic pattern of activity. Prior to applying of a widespread practices of control, wisely assess the intensity of injury really imposed as a result of porcupine's activity. Adopt forestry managing practices which preserve secure shelter refuge to lessen underwood fodder creation (to decrease diet source, boost greater household series and upsurge stress-related wintertime loss). Employ habitation to invite further usual predators for the reason that a thorough raiders managing can impact porcupine's population proliferations. Fence small zones or spaces of possibly great fiscal harms through electric otherwise nonelectric barriers. Install aluminum flashing round matured tree stems and encircle small plants by wire baskets. A few wood preservatives applied to trees might offer partial injury liberation. The greatest substitute method to alleviate injury is to offer alternate salt sources, for instance, salt-impregnated timber. Porcupines might necessity to be controlled, however must not be thoroughly eliminated because these have a vital place in the environment. Thus, finding and treating of the porcupines can be challenging, however, a pest controlling expert has the qualification, tools and abilities needed to efficiently treat a porcupine problematic.

\section{REFERENCES}

1. Sarwar, M. The Species Diversity, Seasonal variation and abundance of rodents (Mammalia: Rodentia) along with their burrows distribution pattern in wheat farmland. Journal of Basic and Applied Research International, 2015;5:48-55.

2. Sarwar, M. Pattern of Damage by Rodent (Rodentia: Muridae) Pests in wheat in conjunction with their comparative densities throughout growth phase of crop. International Journal of Scientific Research in Environmental Sciences, 2015;3: 159-166.

3. Sarwar, M. Species complex, damage pattern and efficiency of rodenticides in controlling rodents attacking rice (Oryza sativa L.) fields. International Journal of Animal Biology, 2015;1 : 202-208.

4. Sarwar, M. The Rodents (Mammalia: Rodentia)Gnawing away on crops and options for the integrated pest management at field. American Journal of Marketing Research 2015;1 : 136-141.

5. Sarwar, M., Ashfaq, M. and Baig, M. Y. The species complex, damage pattern and control of rodents (Mammalia: Rodentia) in Sugarcane (Saccharum officinarum L.) fields. International Journal of Agronomy and Plant Production, 2011;2 : 145-150.

6. Sarwar. M. The rodents (Mammalia: Rodentia)gnawing away on stored grains and options for the integrated pest management in stores. American Journal of Food Science and Health, 2016;2 : 161-168.

7. Allard, M. W., Honeycutt, R. L. and Novacek, M. J. Advances in higher level mammalian relationships. Cladistics, 1999;15:213-219.

8. Grzimek, B. General Introduction. In: B Grzimek, ed. Grzimek's Encyclopedia of Mammals, $1^{\text {st }}$ Edition. New York: Mcgraw-Hill. 1990;1:4-5.
9. Kelt, D. A., and Van Vuren, D. H. The Ecology and Macroecology of Mammalian Home Range Area. American Naturalist, 2001;157:637-645.

10. Helgen, K. M. Major mammalian clades: a review under consideration of molecular and paleontological evidence. Mammalian Biology, 2003;68:1-15.

11. Khan, A. A., Mian, A., and Hussain, R. Deterioration Impact of Indian Crested Porcupine, Hystrix indica, on Irrigated Forest Plantations in Punjab, Pakistan. Pakistan J. Zool., 2014;46 : 1691-1696.

12. Felicetti, L., Shipley, L., Witmer, G., Robbins, C. Digestibility, nitrogen excretion, and mean retention time by North American porcupines (Erithizon dorsatum) consuming natural forages. Physiological and Biochemical Zoology, 2000;73/6:772-780.

13. Wilson, D. E., and Reeder, D. A. M. Mammal Species of the World: A Taxonomic and Geographic Reference, ( $3^{\text {rd }}$ ed.), Johns Hopkins University Press, 1992:2142.

14. Hafeez, S., Khan, G. S., Ashfaq, M. and Khan, Z. H. Food habits of the Indian Crested Porcupine (Hystrix indica) in Faisalabad, Pakistan. Pak. J. Agri. Sci., 2011;48 : 205-210.

15. Siddique, M. M. and Arshad, M. Relative density of porcupine (Hystrix indica) population in forest plantation by food station transect method. Pakistan J. biol. Sci., 2004;7:1745-1749.

16. Li, G. Waring Odor of the North American Porcupine. Journal of Chemical Ecology, 1997;23 : 2737-2754.

17. Fournier, F., Thomas, D. Nitrogen and energy requirements of the North American porcupine. Physoilogical Zoology, 1997;70/6:615-620.

18. Ilse, L., Hellgren, E. Demographic and behavioral characteristics of North American porcupines (Erethizon dorsatum) in pinyon-juniper woodlands of Texas. The American Midland Naturalist, 2001;146/2:329-338.

19. Kashyap, A., Campbell, G. A., Wood, R. J., Rijal, R. K., Langer, R. and Karp, J. M. Microstructured barbs on the North American porcupine quill enable easy tissue penetration and difficult removal. Proceedings of the National Academy of Sciences, 2012;109 : 2128921294.

20. Snyder, M., Linhart, Y. Porcupine feeding patterns: Selectivity by a generalist herbivore?. Canadian Journal of Zoology, 1997;75:2107-2111.

21. Griesemer, S., Fuller, T., Degraaf, R. Habitat use by porcupines (Erethizon dorsatum) in central Massachusetts: effects of topography and forest composition. The American Midland Naturalist, 1998;140/2:271-279.

22. Roberts, T. J. The mammals of Pakistan (revised Ed.). Oxford University Press, Karachi, Pakistan. 1997:525.

23. Khan, A. A., Ahmad, S., Hussain, I. and Munir, S. Deterioration impact of Indian crested porcupine, Hystrix indica, on forestry and agricultural system in Pakistan. International Biodeterioration and Biodegradation, 2000;45:143-149.

24. Roze, U. The North American Porcupine (Second ed.). Cornell University, United States of America: Cornell University Press. 2009:282.

25. Ginsberg, J. R. Biodiversity of mammals. In: Encyclopedia of Biodiversity. S. A. Levin, ed. Academic Press, San Diego, California. 2001;3:777810 .

26. Roze, U., Locke, D. C. Antibiotic Properties of Porcupine Quills. Journal of Chemical Ecology, 1990;16: 725-734. 
27. Sweitzer, R. Breeding movements and reproductive activities of porcupines in the Great Basin Desert. Western North American Naturalist, 2003;63/1:1-10.

28. Karam G. N., Gibson L. J. Biomimicking of animal quills and plant stems: natural cylindrical shells with foam cores. Materials Science and Engineering, 1994;2 (1-2): 113-132.

29. Parker, S. B. Grzimek's Encyclopedia of Mammals, McGraw-Hill, New York. 1990;4.

30. Brooks, E. G. E., Roberton, S. I., Bell, D. J. The conservation impact of commercial wildlife farming of porcupines in Vietnam. Biological Conservation, 2010;143 : 2808-2814.

31. Gurung, K. K., Singh, R. Field Guide to the Mammals of the Indian Subcontinent. San Diego: Academic Press, California. 1996:140.

32. Kadhim, A. H. H. Distribution and reproduction of the Indian Crested Porcupine Hystrix indica (Hystricidae: Rodentia) in Iraq. Zoology in the Middle East, 1997;15 : 9-12.

33. Hafeez, S., Khan, A. A., Gul, S., Nawaz, M. F., Malik, A. A. Determining the Food Habits of Indian Crested Porcupine (Hystrix Indica) in Thal Desert Lands of Punjab, Pakistan. FUUAST J. Biol., 2014;4 : 253-259.

34. Arslan, A. On the Indian crested porcupine, Hystrix indica (Kerr, 1792) in Turkey. Pakistan Journal of Biological Sciences 2008;11:315-317.

35. Hafeez, S, Ashfaq, M, Khan G. S., Khan, Z. H. Damage Inflicted by the Indian Crested Porcupine, Hystrix indica, on Forestry and Agricultural systems in Punjab, Pakistan Journal of Asian and African Studies, 2012;47:168-175.

36. Apfelbach, R., Ganslosser, U. Behavior. In: B Grzimek, ed. Grzimek's Encyclopedia of Mammals, Vol. 1, $1^{\text {st }}$ Edition. New York: Mcgraw-Hill. 1990:160-177.

37. Griesemer, S., DeGraaf R. Denning pattern of porcupines, Erithizon dorsatum. Canadian Field Naturalist, 1996;110/4:634-637.

38. Apfelbach, R. Body Functions. In: B Grzimek, ed. Grzimek's Encyclopedia of Mammals, $1^{\text {st }}$ Edition. New York: Mcgraw-Hill. 1990;1:85-106.
39. Brockman, S. Homeowners guide for resolving wildlife conflicts. Habitat Extension Bulletin No. 45, Wyoming Game and Fish Department, Cheyenne, WY. 1992.

40. Ahmad, M. S., Pervez, A. and Khan, A. A. Deterioration impact and evaluation of control methods of Indian crested porcupine (Hystrix indica) on rangelands in Sindh, Pakistan. J. Nat. Hist. Wildl., 2003;2:19-23.

41. Olson, R., Lewis A. M. Porcupine Ecology and Damage Management Techniques for Rural homeowners. Cooperative Extension Service, College of Agriculture, University of Wyoming, B-1073, 1999:14.

42. Roze, U. The North American porcupine. Smithsonian Institute Press, Washington, D. C. 1989:261.

43. Mushtaq, M., Khan, A. A. and Mian, A. Evaluation of aluminium phosphide fumigation for the control of Indian crested porcupine (Hystrix indica) in scrublands. Paksitan J. Zool., 2008;40:179-183.

44. Khan, A. A. and Mian, A. Field evaluation of coumatetralyl bait against Indian crested porcupine, Hystrix indica Kerr. Pakistan J. Zool., 2008;40:63-64.

45. Knopf, A. A. Audubon society's field guide to North American mammals. (6 $6^{\text {th }}$ ed.). 1989:520.

46. Hafeez, S., Khan, A. R. and Khan, Z. H. Comparative efficacy of some trapping devices used for the control of porcupine, wild boar and other vertebrate pests. Pak. J. Agri. Sci., 2007;44:150-153.

47. Bragg, C. J, Donaldson, J. S. and Ryan, P. G. Density of Cape porcupines in a semi-arid environment and their impact on soil turnover and related ecosystem processes. Journal of Arid Environments, 2005;61:261-275.

48. Nowak, R. M. Walker's Mammals of the World. $5^{\text {th }}$ edition. The John Hopkins University Press, Baltimore and London. 1991:1629.

49. Kurta, A. Mammals of the Great Lakes Region. Ann. Arbor: University of Michigan Press. 1995:376.

50. Schemnitz, SD Porcupines: Damage prevention and control methods. In: Prevention and Control of Wildlife Damage. Cooperative Extension Service, University of Nebraska, Lincoln, 1994:B-81-B-92. 